\title{
Assessment of Drivers' Perceptions of Various Police Enforcement Strategies and Associated Penalties and Rewards
}

\author{
Khaled Shaaban \\ Department of Civil Engineering, Qatar University, P.O. Box 2713, Doha, Qatar \\ Correspondence should be addressed to Khaled Shaaban; kshaaban@qu.edu.qa
}

Received 21 September 2016; Revised 12 November 2016; Accepted 5 December 2016; Published 15 January 2017

Academic Editor: Richard S. Tay

Copyright (C) 2017 Khaled Shaaban. This is an open access article distributed under the Creative Commons Attribution License, which permits unrestricted use, distribution, and reproduction in any medium, provided the original work is properly cited.

\begin{abstract}
Road crashes are a major cause of death in many countries. Qatar has been battling to improve road safety on several fronts using different strategies, including road policing. The purpose of this study is to ascertain drivers' perceptions towards five existing and four proposed police traffic enforcement strategies and associated penalties and rewards in Qatar using face-to-face surveys. The results show that red-light running cameras were perceived to be the most successful existing strategy. The high violation fine and the automation of the system were mentioned as the main reasons for making this strategy the most successful. Three of the existing strategies, fixed-speed enforcement cameras, police enforcement, and mobile speed cameras, were conferred almost the same success percentage, followed by the demerit point system. Regarding the proposed strategies, rewarding safe drivers was selected by the participants as the most successful proposed strategy, followed by introducing more automated enforcement methods. Community service for traffic tickets came in third, followed by defensive driving school. These results can be used to influence future enhancements of existing strategies and guide the development of future traffic strategies being introduced in the traffic system.
\end{abstract}

\section{Introduction}

It has been predicted that traffic fatalities will be the sixth leading cause of death worldwide and the second leading cause of death in developing countries by the year 2020 [1]. Traffic crashes are a major safety and health problem in Qatar, a developing country in the Middle East. Qatar has one of the highest numbers of motor vehicles per 1,000 people (479 motor vehicles per 1,000 people in 2012). The number of daily trips in Qatar jumped from 1,777,000 trips per day in 2000 to $5,498,000$ in 2012 . There were 287,500 vehicles on the roads in Qatar in 2000, compared to 879,039 in 2012. This huge increase has caused more road safety problems. However, the death rate due to road traffic crashes decreased from 35.7 deaths per 100,000 of the population in 2006 to 9.93 in 2014 [2], and Qatar is still battling to increase road safety on several fronts. The country has plans to spend an estimated 100 billion US dollars on infrastructure projects to expand and enhance the quality of the road, water, air, and rail networks [3]. To reduce the growing number of crashes and curb reckless driving in Qatar, different traffic enforcement strategies and a new traffic law stipulating severe penalties were introduced in 2007 [4].

Road policing, traffic enforcement, and associated penalties are extremely important in any successful road safety strategy. However, there is no standard package of enforcement strategies that is suitable for all situations, environments, and cultures. For example, Qatar is the richest country in the world, with a high GDP of $\$ 140,649$ per capita in $2016[5,6]$. Strategies proven to be successful in low-income and middle-income countries may not easily be transferable to a high-income country like Qatar, and they will require careful adaptation and evaluation before implementation. In addition, the population in Qatar consists of people from all over the world, with over 60 different nationalities represented [7]. Qatar also represents a unique phenomenon with regard to the population composition. Unlike many other countries in the world, Qatari nationals (approximately 15\%) [8] constitute a minority in the country. The average Qatari household earns QR72,700 $(\$ 19,918)$ a month, nearly three times the average expat household income of QR24,400 
$(\$ 6,685)$ [9]. Females (approximately $25 \%)$ are also a minority in Qatar [10].

Understanding the perception of enforcement strategies and their penalties by this unique population with an exceptional income composition is important to understand mechanisms of enforcement success and to identify likely political barriers to the continuation or expansion of enforcement. Therefore, the aim of this study is for the participants to reveal their opinions about the acceptability of enforcement or associated penalties and rewards regarding five existing and four proposed strategies. This information is needed to understand the political acceptability of various enforcement types because even if a program is effective at improving safety, it might still be unacceptable to the general population and hence face political pressure for its removal.

Although the evaluation of the effects of various police enforcement types has been undertaken in the literature, there is a lack of research examining public attitudes towards various enforcement types and other incentives and disincentives for behavior. This study is one of the first studies to investigate this subject. This study can help decision makers identify possible future enhancements to improve road safety in Qatar.

\section{Existing Strategies}

Five strategies that currently exist in Qatar were investigated in this study. These strategies are listed below. There are few studies that cover the topic of this study directly. However, there is significant literature describing and evaluating the enforcement modes considered.

2.1. Demerit Point System. A penalty point or demerit point system (DPS) is a system in which a driver's licensing authority, the police force, or another organization issues cumulative demerits or points to drivers who receive convictions for road traffic offenses. The aim of the DPS is to target drivers with frequent traffic violations. A driver's license is suspended once he or she reaches a certain number of points. The DPS has been applied in the traffic law of many countries. Countries, where DPS has been reported to have positive safety effects in the form of a reduction in the traffic violations and/or traffic crashes, include Brazil [11], Ireland [12], Spain [13], and Italy [14]. In 2007, the new traffic law in Qatar introduced a DPS system called "black points," along with a fine system. A certain number of black points are issued against the driver's license for a particular violation. For instance, if a driver runs a red light, he or she is fined QR6,000 $(\$ 1,644)$ and receives seven black points [15]. Once the number of black points exceeds 14 for the first time, the driver's license is suspended for three months. If the same person receives 12 points again, his or her license is suspended for six months, for nine months upon accumulation of another 10 points, and for one year upon accumulation of another eight points.

2.2. Red-Light Cameras. Red-light running (RLR) at traffic signals poses a serious problem by significantly increasing the likelihood of a crash. An RLR crash is said to occur when a driver fails to comply with the red signal and, as a direct effect of that action, collides with another vehicle or a pedestrian [16]. Red-light cameras (RLCs) have been used in many countries for the purpose of yielding a demonstrable reduction in red-light violations. Some studies have found that red-light violations, in addition to angle crashes and leftturn crashes, were reduced significantly with the installation of RLCs [17-19]. Retting et al. reported reductions in red-light violation rates of about $40 \%$ after the introduction of red-light cameras [20,21]. A study in the UK reported an average $18 \%$ reduction in crashes compared to the period before camera installation [22].

In Qatar, RLR was a major issue until the addition of many RLCs in 2007. Many of the intersections in Qatar have RLCs. The current cameras capture a video that shows the image of a vehicle when it enters an intersection against a red traffic signal. This system continuously monitors the traffic signal, and the camera is triggered by any vehicle entering the intersection following a specified time after the signal has turned red. Running a red-light automatically generates a violation, resulting in penalty points and a fine that starts at QR6,000 (\$1,643) [23]. The date, time, location, and vehicle speed are recorded, along with a photograph of the offending vehicle. In Qatar, RLCs also monitor speed and work during the green signal phases. If a driver accelerates to pass through the intersection while the light is still green and exceeds the speed limit, a speeding violation is automatically issued. The cameras are installed at major intersections, intersections with high crash rates, intersections with speeding problems, and intersections with a high number of RLR violations.

2.3. Fixed-Speed Cameras. Speed cameras monitor traffic speeds using radar technology and photograph drivers traveling above the speed limit. This type of camera is unaccompanied by officers. Most speed cameras use radar signals to detect speeding vehicles and trigger a camera and flash unit to photograph vehicles traveling faster than the set speed. The date, time, location, and vehicle speed are recorded, along with a photograph of the offending vehicle. Fixedspeed camera enforcement is most appropriate if crashes are clearly concentrated in specific road sections and are related to excess speed. For example, if it is necessary for vehicles to slow down on a specific section of the road, for example, an intersection or a nearby school, it is more effective to have a visible fixed-speed camera, preferably accompanied by a warning sign. The drivers' awareness of speed camera locations and warning sign boards make them drive within the speed limit in those areas. This approach increases the preventative effect; when drivers know that there is a chance of detection, they tend to maintain the speed limit.

In Canada, the use of speed cameras was found to be associated with a $9 \%$ reduction in crashes [24]. A metaanalysis of 10 studies of the local effect of speed cameras in seven European countries found a decrease of 19\% in injurycausing crashes [25]. Another study in the UK reported an average $28 \%$ reduction in crashes and a $2.4 \mathrm{mph}$ decrease in speeds at the operating sites compared to the period before the camera installation [22].

One of the problems with these types of cameras is that drivers tend to reduce their vehicle speed when approaching 
speed cameras and then increase speed as soon as they pass the camera, which is known as the halo effect [26]. A study in Kuwait compared speed data measured at the deployment locations of speed cameras and those at two control locations approximately $1 \mathrm{~km}$ before and after the speed cameras. It was found that the difference in speed measured at and away from the speed cameras was statistically significant. The authors concluded that without live police enforcement of traffic rules and regulations to augment automatic control devices, the effectiveness of the speed cameras was insignificant [27]. Other research has shown that this method was effective in reducing vehicle speeds and violations in the vicinity of speed cameras. It was not so effective in reducing vehicle speeds on the road sections beyond the influence area of speed cameras, which was less than one $\mathrm{km}[28]$.

In Qatar, speed cameras are installed at all intersections with RLCs and key high crash/speeding locations. The fine charged for speeding in Qatar starts at QR500 (\$137) for exceeding the speed limit, and it increases by QR100 (\$27.4) for every $10 \mathrm{~km} /$ hour of speed, up to the maximum penalty of QR1,000 (\$274). Speed violators are also charged four black points to their license according to the Qatar Traffic Law, which makes this strategy work more successfully [23].

2.4. Mobile Speed Cameras. Another enforcement method used in Qatar is mobile speed cameras. Mobile cameras are accompanied by enforcement officers that may move among various locations. Unlike static speed cameras, which are operated remotely from permanent camera housings at the roadside, mobile cameras operate in this situation from parked vehicles and can be quickly moved from one site to another. These cameras capture the license plates of passing vehicles exceeding a speed above the legal limit and mail a fine and penalty points to the driver of the vehicle. Mobile cameras tend to be rotated around a much larger number of sites than static cameras and operated at specific times, whereas static cameras typically operate around the clock all year. These differences result in fewer hours of operation at each mobile camera site than at static camera sites. Mobile cameras might be expected to be less effective than static cameras when effectiveness is measured in terms of reductions in injurious crashes per annum because of the differences in enforcement intensity. The advantage of mobile speed cameras is their unpredictability, which creates a general deterrence against speeding, leading to crash reductions across the entire network [29]. A previous study in New Zealand demonstrated reductions in crashes involving injuries of up to $32 \%$ in urban and $14 \%$ in rural areas when mobile speed cameras were integrated with more general road safety campaigns [30]. Another study in England showed that crashes decreased by $19 \%$ and fatal and serious crashes decreased by $44 \%$ at mobile speed camera sites [31].

2.5. Police Enforcement. Police enforcement is one of the main methods of enforcement used in Qatar. The primary duty of police enforcement is the enforcement of traffic laws through stopping the vehicles on roadsides and giving tickets for different violations, such as not wearing a seat belt, using a cell phone while driving, reckless driving, and so forth. The recognizable image of a police vehicle stopped at the side of the road, with the officer taking enforcement actions, attracts the attention of most passing drivers. Evidence suggests that the threat of being caught is a strong motivation for most drivers to obey motor vehicle laws [32]. Stationary road policing was consistently found to produce significant speed reduction effects in almost all of the studies conducted so far. Circulating police patrol was found to be less effective than stationary police enforcement in a comparative study, and this was also reflected in the overall results from the literature [33]. However, Axup [34] has suggested that the impact is only short term, and that highly visible enforcement strategies are often compromised by drivers simply adapting their behavior at the site of enforcement activity.

\section{Proposed Strategies}

Another objective of this study was to ascertain driver perceptions of four new strategies used in other countries but currently not used in Qatar. The selection process of these four strategies was achieved using a focus group conducted through the Qatar National Traffic Safety Committee (QNTSC) and specifically through the Research and Studies Subcommittee (RSSC) formed under the QNTSC with the purpose of conducting research and studies focusing on traffic safety. QNTSC was formed with the main purpose of developing the Qatar National Road Safety Strategy and overseeing, monitoring, and coordinating the activities of such a strategy. The QNTSC has professional members from different organizations that share knowledge of and interest in traffic safety.

The RSSC has members working for different organizations, including Qatar University, Hamad Hospital (the main public hospital in Qatar), the Ministry of Development Planning and Statistics, the Higher Council for Family Affairs, the Public Works Authority, the Ministry of Transport, the General Secretariat for Development Planning, the Qatar Foundation for Education, Science, and Community Development, the Traffic Engineering and Safety Department at the Ministry of Interior (MOI), the Legal Affairs Department at the MOI, and the National Traffic Safety Committee at the MOI. A total of ten people (one person per organization) were involved in the focus group. The focus group meetings were held at the official location for QNTSC at the MOI. For the purpose of this study, the focus group was focused on one goal related to recommending various road policing strategies and associated penalties and rewards that are suitable and can be implemented in Qatar. The moderator introduced the goal of the focus group to the participants, asked them open-ended questions, and managed the discussions so as to avoid forcing any specific answers among the participants. A note-taker handled and reported the recording of the discussions and took notes. The outcome of the focus group resulted in the strategies listed below.

3.1. Rewarding Safe Drivers. This strategy is based on rewarding law-abiding drivers by giving them incentives, as opposed 
to the other, fear-oriented strategies. The idea is to encourage drivers to apply safety standards and follow regulations rather than penalize them. This strategy is the only one in the four investigated strategies that looks at driving skills rather than violations. Rewarding drivers motivates them to improve their driving skills and abide by the traffic rules. However, Hurst [35] has argued that attempts to reward safe driving are not likely to produce any useful results. He mentions that insurance rebates, such as no-claims bonuses, are appropriate rewards for good behavior, but they are so hopelessly delayed that it is hard to see how they can reinforce specific safe driving behaviors.

In a similar experiment, the Police in Dubai, United Arab Emirates (UAE), launched in 2012 a rewarding strategy called "white points" for registered drivers to encourage motorists to follow traffic rules and regulations and promote safe driving. To be eligible for the system, a driver must maintain a clean record throughout the year, which also means incurring no fines on his or her license. The system allows motorists to win a maximum of 24 white points during a year. Drivers lose two points if there are any traffic law violations during any month. One thousand prize winners were selected from among 300,000 drivers who maintained a clean record during 2013. Prizes included vouchers from retailers, mobile phones, airline tickets, and other things worth not less than \$200 [36]. It is interesting to study the opinion of the drivers regarding this strategy. Given that Qatar is the richest country in the world, people may not look forward to monetary rewards, which may reduce the possibility of making this strategy successful. The system proposed in this study replicates the system used in Dubai, UAE.

3.2. Defensive Driving Course. Some countries developed programs that can help offenders by providing them with the information and skills necessary to develop positive attitudes towards driving and develop safer driving behaviors in the form of defensive driving course. These types of courses are offered for offenders who have pleaded guilty or found guilty of specific traffic offenses. In this case, the court refers the offenders to an approved traffic course provider in order to complete a nominated course. The case is then adjourned for sentencing, allowing sufficient time for the course to be completed. For example, the Traffic Offender Intervention Program in New South Wales, Australia, addresses offenses such as driving under the influence (DUI), speeding, driver fatigue, and occupant restraint $[37,38]$.

For the case of Qatar, the high average income can render fines ineffective as a punishment method. In this study, this strategy is based on forcing drivers to take a defensive driving course (DDS) for two of the worst violations according to the traffic laws in Qatar: (1) excessive speeding violation (exceeding the speed limit by more than $40 \mathrm{~km} / \mathrm{hr}$ ) and (2) running a red-light and speeding at the same time. If a driver receives a ticket for one of these two violations, he or she must attend a basic driver improvement course as well as pay a fine and have points added to their license. This strategy is currently available in many countries in different forms. For example, in some states in the United States, drivers can voluntarily complete a DDS course for an automatic point reduction, fee reduction, or auto insurance discount [39]. In other states, taking a DDS course is mandatory in cases of extreme violations, such as extreme cases of DUI or after crashes that involve death or serious injury [40]. One study showed that these types of courses could lead to a decrease in the frequency of traffic violations by about $10 \%$ [41]. In another study, an evaluation of road crash records for the 12month periods before and after course attendance indicated that the DDC was not effective in reducing crashes for 1719-year-old drivers or for female drivers aged over 20 years; however, significant crash reductions were found for male drivers aged 20-39 years [42].

3.3. Community Service for Traffic Tickets. For the situation in Qatar, it was necessary to find other strategies that did not depend solely on paying fines as a punishment method. Community service for traffic tickets is a system that helps drivers to improve after violating one of the rules by requiring them to work as volunteers instead of making them pay a fine. It is human nature to prefer a positive way to pay for the consequences of mistakes [43].

In Baton Rouge, Louisiana, a program requires alcoholrelated traffic offenders to do community service at different organizations approved by the city court. The community service varies from general tasks to professional services for skilled offenders [43]. In Marion County, California, a program deducts $\$ 10$ off the fine for each hour of community service at a nonprofit organization. The court has a list of approved community service organizations. In Shasta County, California, a traffic ticket fine can be reduced by $\$ 50$ for every eight hours of community service put in. In Pasco County, Florida, a program offers a similar alternative, allowing residents who can demonstrate financial hardship to pay off fines through public works or community service projects [44]. A similar strategy can be used in Qatar for specific types of violations. In this study, the strategy is not intended to be used in the case of financial hardship but to be used for two high-risk violations: excessive speeding $(40 \mathrm{~km} / \mathrm{hr}$ over the speed limit) or a combination of running a red-light and speeding.

3.4. Additional Automated Enforcement Methods. Currently, the only technology solutions used in Qatar are RLCs and speed cameras (fixed and mobile). The new proposed strategy depends on adding another automated enforcement method. In this study, one additional automated strategy was recommended, which includes new cameras that can be used to detect and fine drivers and passengers who do not wear seat belts, drivers that use their cell phone while driving, and drivers who display aggressive behavior, such as tailgating. The operators of these types of cameras can zoom in and snap offending drivers from a distance long before motorists spot the camera. Similar cameras have been investigated in Australia [45]. The Dubai Traffic Police have already tested similar technologies to enforce tailgating. According to officials, the new technology proved six times more efficient than conventional technologies [46]. 


\section{Data Collection}

The face-to-face survey method was used for this study. This method allows participants to ask questions if any of the proposed strategies is not clear. The four proposed strategies were explained in detail in the survey form. The survey design relied on open-ended questions using a short structured interview. The question stated "Do you consider the following methods to be acceptable/unacceptable enforcement methods? Moreover, why?" An open-ended questionnaire was used in order for the participants to justify their choice and to make the answers more of a revealed opinion than a stated opinion. This approach allows the respondents to suggest different possibilities that may not be known to the research team, reduces the bias in the responses, forces the participant to think carefully about his or her answer, and makes it easier to explain why he or she selected this answer. It can also encourage the participant to believe that his or her responses matter. The questionnaire was designed to be easy to understand, written in simple English/Arabic, and as short as possible to prevent participant boredom.

4.1. Pilot Survey. Before conducting the actual questionnaire, a pilot survey was administered to ensure that the survey form was easy to understand and could be completed in a reasonable time. In the beginning, the interviewers introduced themselves and the overall aim of the study. To reduce the possibility of bias in the answers, it was clearly explained to the participants that this questionnaire is conducted only for the purpose of research and will not be utilized in the future to implement or change any existing or proposed enforcement. This explanation was important to discourage a participant from strategically answering questions based on how he or she would like to see a policy implemented or removed or from giving answers that he or she thinks the interviewer expects. It was also made clear that the interviewers were available to answer any questions about anything that was not clear in the form, especially related to the four proposed strategies.

The preliminary questionnaire included an explanation of the different strategies, in addition to an explanation of the advantages and disadvantages of each strategy obtained from the focus group. The feedback received from the participants indicated that including the advantages and disadvantages made the questionnaire lengthy. Others felt that including the advantages and disadvantages could lead the participants to a specific answer. Therefore, it was decided to remove this part from the final questionnaire. Also, the pilot survey revealed weak sentence structures in some cases and difficult technical terms in other cases when describing some of the proposed strategies. The descriptions of the proposed strategies were thus improved and simplified.

The pilot study was also conducted by approaching drivers in a parking lot after they parked their vehicles to ensure the targeting of driver participants. However, the response rate during the pilot study was very low, and many drivers refused to stop due to the hot weather of Doha. Therefore, it was decided to hand out the survey forms in more convenient locations.
4.2. Sample Size and Final Survey. The demographic questions were an important aspect of this survey and were designed to determine whether these factors might influence a driver's answers and opinions. Age, gender, and nationality were the only demographic information collected in the study. The minimum sample size was estimated as follows:

$$
\mathrm{SS}=Z^{2} * \frac{p(1-p)}{C^{2}},
$$

where SS is sample size, $Z$ is $Z$-value, $p$ is percentage of population, and $C$ is confidence interval.

Assuming a $95 \%$ confidence level $(Z=1.96)$ and a $5 \%$ significance interval $(C=0.05)$, the minimum sample size was 385 [47]. The target population for this research was all the drivers in Qatar. The preferred method to reach this population is through a random sampling. However, due to budget limitations, it was decided to use a convenience sampling method instead and regularly monitor the demographics, such as gender and nationality, to ensure that the sample was fairly representative.

This survey was limited to people older than 18 years with a valid driving license, who regularly drive a vehicle and reside in Qatar. In this study, 500 survey forms were printed and distributed among the drivers in different locations, including universities, shopping malls, company cafeterias, and sports clubs. To ensure randomization, the trained interviewers approached every 10th person entering, explained the importance of the questionnaire, and asked them if they met the criteria and if they were willing to do the survey. If they approved, the interviewers explained the questionnaires to each driver in person and then handed out the survey forms to the participants. The participants were asked to complete the forms by hand and return them then and there. The participants were given the chance to ask any questions during the process if any part of the forms was not clear.

A total of 446 survey forms were considered complete and used in the analysis. The remaining forms either had more than 30\% missing responses or were not returned, and hence they were disregarded. Each interviewer handled converting his or her surveys from their paper form to electronic sheets to process them further. Coding was then conducted to translate the answers into two possible outcomes (successful/unsuccessful). The survey papers and the data entered were entered again by another team that was not involved in the data collection process to ensure quality. This step was necessary because the coding of the open-ended questions increases the likelihood of bias during the coding process. The results were compared, and any conflicts in the results were verified and revised by the author.

The distribution of data collected is given in Table 1. The characteristics of the participants were generally representative of the characteristics of the population in Qatar; however, there were some differences. The sample is $76.9 \%$ male and $23.1 \%$ female. This difference can be explained by the imbalanced population in Qatar (which is $75.5 \%$ male and $24.5 \%$ female) [10]. The percentage of the Qatari drivers in this study is $22.4 \%$, whereas only $14.3 \%$ of the general population are Qataris [8]. This oversampling in this study 
TABLE 1: Gender, age, and nationality of the participants.

\begin{tabular}{lcc}
\hline & Frequency & Percentage \\
\hline Gender & 343 & \\
Male & 103 & $76.9 \%$ \\
Female & & $23.1 \%$ \\
Age & 171 & \\
18-25 & 173 & $38.3 \%$ \\
$26-50$ & 102 & $38.8 \%$ \\
51+ & & $22.9 \%$ \\
Nationality & 100 & \\
Qatari & 230 & $22.4 \%$ \\
Non-Qatari Arab & 116 & $51.6 \%$ \\
Others & 446 & $26.0 \%$ \\
\hline Total & & $100.0 \%$ \\
\hline
\end{tabular}

TABLE 2: Variable coding and definitions.

\begin{tabular}{lc}
\hline Variable & Description \\
\hline $\begin{array}{l}\text { Dependent variable } \\
\text { Strategy success }\end{array}$ & Unsuccessful: 0 , successful: 1 \\
\hline $\begin{array}{l}\text { Independent variable } \\
\text { Gender }\end{array}$ & Male $^{*}: 1$, female: 2 \\
Age group & $18-25^{*}: 0,26-50: 1,51$ or more: 2 \\
Nationality & Qatari $^{*}: 1$, non-Qatari Arab: 2 , others: 3 \\
\hline
\end{tabular}

${ }^{*}$ Reference group for binary logistic analysis.

was necessary to ensure that there are enough members of the Qatari subgroup in the population so that more reliable estimates can be reported for that group. The oversampling allows for the overall survey results to represent both the majority non-Qatari population and the Qatari nationals subgroup.

\section{Binary Logistic Regression}

Logistic regression was used in the analysis of this study. This type of analysis is one of the most useful assessment methods to determine which factors influence the outcome response of participants, given that it intrinsically adjusts each factor considered for the presence of the other factors. Binary logistic regression is an appropriate statistical technique when the independent variable is binary. It represents two groups of interest, with values of 0 and 1 , such as being successful or unsuccessful in this study. The procedure for estimating coefficients is a maximum likelihood, and the goal is to find the best linear combination of independent variables to maximize the likelihood of obtaining the observed outcome frequencies.

As shown in Table 2, the response variable (strategy success) is binary (dichotomous) with two levels: 0: unsuccessful and 1: successful. For the independent variables, three categorical variables were included: driver gender $(1=$ male and $2=$ female $)$, driver nationality $(1=$ Qatari, $2=$ non-Qatari Arab, and $3=$ other $)$, and driver age $(18-25=1,26-50=2$, and 51 or older $=3$ ).
In the model, the logit is the natural logarithm of the odds or the likelihood ratio with the dependent variable. The probability $P 1$ of a successful strategy $Y 1$ [48] is as follows:

$$
\begin{aligned}
& Y 1=\operatorname{Logit}(P 1)=\ln (P 1|1-P 1|), \\
& Y 1=\beta_{0}+\beta_{1} x_{1}+\beta_{2} x_{2}+\cdots+\beta_{p} x_{p},
\end{aligned}
$$

where $Y 1$ is latent variable for strategy success, $P 1$ is probability of a successful strategy, $x_{j}$ is value of $j$ th independent variable, and $\beta_{j}$ is corresponding coefficient for the $j$ th independent variable.

With the latent variable, the conditional probability of a possible outcome is determined as follows:

$$
P(\text { Successful Strategy })=\pi_{x}=\frac{\exp (Y 1)}{1+\exp (Y 1)} .
$$

Logistic regression determines the coefficient that makes the observed outcome, namely, a successful strategy, in the model most likely using the maximum likelihood method. The independent variables could be continuous or dichotomous. The software used in this study is SPSS Statistics (version 23). Odds ratios (OR) representing measures of the association are presented for different models. The odds ratios indicate the increased risk compared to the referred group. In addition, $95 \%$ confidence intervals for the reliability of the odds ratio estimates are calculated and presented.

\section{Assessment of Existing Strategies}

6.1. Red-Light Cameras. The red-light camera strategy was revealed as the most successful according to participants, with $87.2 \%$ of participants on average rating it as successful, and $80 \%$ or more of all demographics rating it as successful. As shown in Table 3, the binary logistic regression model did not identify any significant factors directly associated with the proposed strategy being successful. There was no significant relationship between the red-light camera strategy and the gender, age, or nationality of the respondents at the $5 \%$ significance level. All categories related to gender, age, and nationality found the strategy successful.

The participants felt that the high fine for running a redlight is a key factor in the success of this method. In addition, the high number of black points (seven points), which is the highest among the other violations, assigned for this violation was also cited as a major reason for the success of this method. It was mentioned that because the RLCs are obvious and placed clearly on the road, impatient drivers are discouraged from running red lights. Finally, the participants commented that the red-light camera system, being fully automated, is fair because it does not involve any humans, and it collects all of the evidence needed to prosecute red-light violators.

In terms of disadvantages, the participants mentioned that not all the signalized intersections are equipped with RLCs, so drivers run the red lights at intersections without them. In addition, some cameras are hit by vehicles or become damaged, and it takes a long time to fix them. It was mentioned that some RLCs are not visible at some locations, so they are not effective. Furthermore, the cameras capture the 
TABLE 3: Reported success and logistic model results for the red-light cameras strategy.

\begin{tabular}{|c|c|c|c|c|c|c|c|c|c|}
\hline \multirow{2}{*}{ Red light cameras } & \multirow{2}{*}{ Total } & \multicolumn{2}{|c|}{ Gender } & \multicolumn{3}{|c|}{ Age } & \multicolumn{3}{|c|}{ Nationality } \\
\hline & & Male & Female & $18-25$ & $26-50$ & $51+$ & Qatari & Non-Qatari Arab & Others \\
\hline Unsuccessful & 57 & 42 & 15 & 18 & 24 & 15 & 18 & 26 & 13 \\
\hline Successful & 389 & 301 & 88 & 153 & 149 & 87 & 82 & 204 & 103 \\
\hline$\%$ of success & $87.2 \%$ & $87.8 \%$ & $85.4 \%$ & $89.5 \%$ & $86.1 \%$ & $85.3 \%$ & $82.0 \%$ & $88.7 \%$ & $88.8 \%$ \\
\hline \multirow{2}{*}{\multicolumn{2}{|c|}{ Variable }} & \multirow{2}{*}{$B$} & \multirow{2}{*}{ SE } & \multirow{2}{*}{ Wald } & \multirow{2}{*}{ df } & \multirow{2}{*}{ Sig. } & Odds ratio & \multicolumn{2}{|c|}{$95 \% \mathrm{CI}$ for $\operatorname{EXP}(B)$} \\
\hline & & & & & & & $\operatorname{Exp}(B)$ & Lower & Upper \\
\hline \multicolumn{2}{|c|}{ Age [26-50] versus [18-25] } & -.274 & .338 & .657 & 1 & .418 & 0.760 & .392 & 1.475 \\
\hline \multicolumn{2}{|c|}{ Age [51 or more] versus [18-25] } & -.366 & .380 & .928 & 1 & .335 & .694 & .330 & 1.460 \\
\hline \multicolumn{2}{|c|}{ Gender [female] versus [male] } & -0.224 & .329 & 0.464 & 1 & .496 & 0.799 & 0.419 & 1.523 \\
\hline \multicolumn{2}{|c|}{ Nationality [non-Qatari Arab] versus [Qatari] } & .532 & .338 & 2.487 & 1 & .115 & 1.703 & .879 & 3.300 \\
\hline \multicolumn{2}{|c|}{ Nationality [others] versus [Qatari] } & .590 & .395 & 2.229 & 1 & .135 & 1.803 & .832 & 3.909 \\
\hline \multicolumn{2}{|l|}{ Constant } & 1.767 & .343 & 26.547 & 1 & .000 & 5.854 & & \\
\hline
\end{tabular}

$B$ : coefficient for the constant in the null model, SE: standard error around the coefficient for the constant, Wald statistic: test that tests the null hypothesis that the constant equals 0 , df: degrees of freedom for the Wald statistic test, and $\operatorname{Exp}(B)$ : exponentiation of the $B$ coefficient, which is an odds ratio.

plate number during the violation, and the penalty and black points are charged against the vehicle owner. In some cases, the owner of the vehicle has to bear the consequences for other family members or for a friend who was driving at the time of the violation and committed the offense, unless the violating driver goes to the traffic department and admits that he or she is the violator. Finally, some participants mentioned that some drivers ask their friends or chauffeurs to go to the traffic department and take the blame for the violation in order to avoid getting black points against their driver's license.

6.2. Police Enforcement. This strategy emerged as the second most successful strategy, with a $68.4 \%$ success rate (compared to $87.2 \%$ for the first strategy). Non-Qatari Arabs (69.1\%) and other nationalities (75.9\%) found this strategy more successful than the Qatari nationals (58\%). The binary logistic regression model found no significant relationship between the police enforcement strategy and the gender or nationality at the $5 \%$ significance level. However, there was a strong relationship between the police enforcement variable and the age of the respondents. As shown in Table 4, the model showed that the odds of older drivers considering the police enforcement strategy successful are 2.3 times higher than the odds of younger drivers considering it successful.

The participants stated that the primary advantage of police enforcement is that it is difficult to avoid an officer on the road as he takes action against violations then and there, unlike the other types of enforcement. They also mentioned that police officers could verify multiple violations at the same time, such as speed violations, use of mobile phones, and not wearing seat belts. Officers can also understand complicated situations and circumstances and serve as reliable witnesses. Participants also mentioned that police enforcement makes it difficult for the driver of the vehicle at the time of violation to escape punishment by saying that someone else was driving the vehicle, as in the case of automated violations.

Participants mentioned that the number of police officers seen on the roads for the purpose of traffic enforcement is low, which they considered a disadvantage. They also stated that police officer presence is reduced during the middle of the day due to the extremely hot weather conditions in Qatar. Traffic police officers in Qatar are also more focused on organizing traffic in busy locations and in assisting in emergencies than in giving out tickets. Respondents also felt that police officers that patrol in special areas or locations do not get involved in giving traffic violations. Others mentioned that some police officers are not motivated to give traffic tickets. Still other respondents mentioned that there is bias involved in how traffic rules are enforced by police officers. These respondents felt that automated enforcements are unbiased, whereas Qatar police officers are not always fair when they pull over drivers, tending to favor men over women and Qatari nationals over other nationalities. In addition, participants stated that some drivers may succeed in influencing the police officers and thus escape the penalties. This is known as the phenomenon of punishment avoidance, where drivers succeed to avoid a ticket by talking themselves out of a ticket [49]. Finally, they mentioned that police officers do not typically issue warnings but that they should give warnings and explain the rules and regulations to the driver if it is their first violation.

6.3. Fixed-Speed Enforcement Cameras. About $67 \%$ of the drivers supported fixed-speed camera enforcement as a successful strategy. Older drivers and non-Qatari drivers found this strategy more successful than others. The binary logistic regression model identified significant factors directly associated with the proposed strategies being perceived as successful. Table 5 lists the model estimation and the odds ratio for the independent variables. The model showed that the odds of older drivers considering this strategy successful are 2.4 times higher than the odds of younger drivers considering it successful.

Participants felt that knowing that there are many speed cameras on the road causes many drivers to reduce their speed while driving. Participants also stated that these cameras work especially well at intersections because people often speed to go through the intersection before the signal 
TABLE 4: Reported success and logistic model results for the police enforcement strategy.

\begin{tabular}{|c|c|c|c|c|c|c|c|c|c|}
\hline \multirow{2}{*}{ Police enforcement } & \multirow{2}{*}{ Total } & \multicolumn{2}{|c|}{ Gender } & \multicolumn{3}{|c|}{ Age } & \multicolumn{3}{|c|}{ Nationality } \\
\hline & & Male & Female & $18-25$ & $26-50$ & $51+$ & Qatari & Non-Qatari Arab & Others \\
\hline Unsuccessful & 141 & 109 & 32 & 60 & 62 & 19 & 42 & 71 & 28 \\
\hline Successful & 305 & 234 & 71 & 111 & 111 & 83 & 58 & 159 & 88 \\
\hline$\%$ of success & $68.4 \%$ & $68.2 \%$ & $68.9 \%$ & $64.9 \%$ & $64.2 \%$ & $81.4 \%$ & $58.0 \%$ & $69.1 \%$ & $75.9 \%$ \\
\hline \multirow{2}{*}{ Variable } & & \multirow{2}{*}{$B$} & \multirow{2}{*}{ SE } & \multirow{2}{*}{ Wald } & \multirow{2}{*}{$\mathrm{df}$} & \multirow{2}{*}{ Sig. } & Odds ratio & \multicolumn{2}{|c|}{$95 \% \mathrm{CI}$ for $\operatorname{EXP}(B)$} \\
\hline & & & & & & & $\operatorname{Exp}(B)$ & Lower & Upper \\
\hline \multicolumn{2}{|c|}{ Age [26-50] versus [18-25] } & -.035 & .231 & .023 & 1 & .879 & 0.965 & .614 & 1.518 \\
\hline \multicolumn{2}{|c|}{ Age $\left[51\right.$ or more] versus $[18-25]^{*}$} & .852 & .305 & 7.796 & 1 & .005 & 2.345 & 1.289 & 4.265 \\
\hline \multicolumn{2}{|c|}{ Gender [female] versus [male] } & -0.002 & .249 & 0.000 & 1 & .993 & 0.998 & 0.612 & 1.626 \\
\hline \multicolumn{2}{|c|}{ Nationality [non-Qatari Arab] versus [Qatari] } & .516 & .254 & 4.125 & 1 & .042 & 1.676 & 1.018 & 2.757 \\
\hline \multicolumn{2}{|c|}{ Nationality [others] versus [Qatari] } & .802 & .301 & 7.085 & 1 & .008 & 2.229 & 1.235 & 4.023 \\
\hline \multicolumn{2}{|c|}{ Constant } & .158 & .249 & 0.400 & 1 & .527 & 1.171 & & \\
\hline
\end{tabular}

${ }^{*}$ It refers to significance at 5 percent level.

TABLE 5: Reported success and logistic model results for the fixed-speed enforcement cameras strategy.

\begin{tabular}{|c|c|c|c|c|c|c|c|c|c|}
\hline \multirow{2}{*}{ Fixed-Speed Enforcement Cameras } & \multirow{2}{*}{ Total } & \multicolumn{2}{|c|}{ Gender } & \multicolumn{3}{|c|}{ Age } & \multicolumn{3}{|c|}{ Nationality } \\
\hline & & Male & Female & $18-25$ & $26-50$ & $51+$ & Qatari & Non-Qatari Arab & Others \\
\hline Unsuccessful & 149 & 109 & 40 & 64 & 64 & 21 & 40 & 73 & 36 \\
\hline Successful & 297 & 234 & 63 & 107 & 109 & 81 & 60 & 157 & 80 \\
\hline$\%$ of success & $66.6 \%$ & $68.2 \%$ & $61.2 \%$ & $62.6 \%$ & $63.0 \%$ & $79.4 \%$ & $60.0 \%$ & $68.3 \%$ & $69.0 \%$ \\
\hline \multirow{2}{*}{ Variable } & & \multirow{2}{*}{$B$} & \multirow{2}{*}{ SE } & \multirow{2}{*}{ Wald } & \multirow{2}{*}{$\mathrm{df}$} & \multirow{2}{*}{ Sig. } & Odds ratio & \multicolumn{2}{|c|}{$95 \%$ CI for $\operatorname{EXP}(B)$} \\
\hline & & & & & & & $\operatorname{Exp}(B)$ & Lower & Upper \\
\hline \multicolumn{2}{|l|}{ Age [26-50] versus [18-25] } & .076 & .228 & .111 & 1 & .739 & 1.079 & .690 & 1.687 \\
\hline \multicolumn{2}{|l|}{ Age $\left[51\right.$ or more] versus $[18-25]^{*}$} & .879 & .296 & 8.804 & 1 & .003 & 2.407 & 1.347 & 4.301 \\
\hline \multicolumn{2}{|c|}{ Gender [female] versus [male] } & -0.359 & .239 & 2.255 & 1 & .133 & 0.699 & 0.437 & 1.116 \\
\hline \multicolumn{2}{|c|}{ Nationality [non-Qatari Arab] versus [Qatari] } & .438 & .255 & 2.950 & 1 & .086 & 1.550 & .940 & 2.556 \\
\hline \multicolumn{2}{|c|}{ Nationality [others] versus [Qatari] } & .381 & .291 & 1.711 & 1 & .191 & 1.463 & .827 & 2.589 \\
\hline \multicolumn{2}{|l|}{ Constant } & .248 & .249 & 0.993 & 1 & .319 & 1.281 & & \\
\hline
\end{tabular}

* It refers to significance at 5 percent level.

turns red, but the high penalty fines for speeding through an intersection make the drivers reduce their speed.

Disadvantages mentioned by the participants include the fact that it is easy to avoid this enforcement because drivers are aware of the locations of the cameras and regulate their speed only at these locations. They also stated that the absence of the fixed cameras on all roads and inappropriate placing of said cameras without adequate spacing reduce their effectiveness. In addition, clearly visible fixed-speed cameras may tempt drivers to speed up a few hundred meters after they leave the camera's range. Finally, participants stated that the fixed-speed camera enforcement cases are charged based on the vehicle plate number. In this case, the car owner may bear the consequences of the negligence of another who drove his or her car, and dishonest administration of black points to innocent drivers may occur.

6.4. Mobile Speed Cameras. The movable speed camera strategy came in fourth place: $66.1 \%$ of drivers mentioned it as a successful strategy. There was a significant relationship between the perceived success of the police enforcement strategy and the age, gender, and nationality of the respondents at the 5\% significance level. Table 6 lists the model estimation and the odds ratio for the independent variables. The model showed that the odds that old drivers will consider mobile speed cameras as a successful strategy are 1.9 times higher than the odds that male drivers will consider them a success. Finally, the odds of other nationalities considering the mobile speed cameras a successful strategy are 2.6 times higher than the odds of the Qatari nationals considering them successful.

The participants mentioned the following advantages of this strategy: mobile cameras are more difficult to avoid than fixed cameras, and they remind drivers that speed detection can occur anywhere and anytime. These comments indicate that many participants feel that this type of enforcement is unpredictable and fair because it does not involve any humans, and it collects all of the evidence needed to prosecute 
TABLE 6: Reported success and logistic model results for the mobile speed cameras strategy.

\begin{tabular}{|c|c|c|c|c|c|c|c|c|c|}
\hline \multirow{2}{*}{ Mobile speed cameras } & \multirow{2}{*}{ Total } & \multicolumn{2}{|c|}{ Gender } & \multicolumn{3}{|c|}{ Age } & \multicolumn{3}{|c|}{ Nationality } \\
\hline & & Male & Female & $18-25$ & $26-50$ & $51+$ & Qatari & Non-Qatari Arab & Others \\
\hline Unsuccessful & 151 & 127 & 24 & 65 & 62 & 24 & 42 & 85 & 24 \\
\hline Successful & 295 & 216 & 79 & 106 & 111 & 78 & 58 & 145 & 92 \\
\hline$\%$ of success & $66.1 \%$ & $63.0 \%$ & $76.7 \%$ & $62.0 \%$ & $64.2 \%$ & $76.5 \%$ & $58.0 \%$ & $63.0 \%$ & $79.3 \%$ \\
\hline \multirow{2}{*}{ Variable } & & \multirow{2}{*}{$B$} & \multirow{2}{*}{ SE } & \multirow{2}{*}{ Wald } & \multirow{2}{*}{ df } & \multirow{2}{*}{ Sig. } & Odds ratio & \multicolumn{2}{|c|}{$95 \% \mathrm{CI}$ for $\operatorname{EXP}(B)$} \\
\hline & & & & & & & $\operatorname{Exp}(B)$ & Lower & Upper \\
\hline \multicolumn{2}{|c|}{ Age [26-50] versus [18-25] } & -.025 & .232 & .012 & 1 & .914 & 0.975 & .619 & 1.536 \\
\hline \multicolumn{2}{|c|}{ Age [51 or more] versus [18-25] } & .599 & .288 & 4.320 & 1 & .038 & 1.820 & 1.035 & 3.202 \\
\hline \multicolumn{2}{|c|}{ Gender [female] versus [male] } & 0.682 & .265 & 6.635 & 1 & .010 & 1.979 & 1.177 & 3.326 \\
\hline \multicolumn{2}{|c|}{ Nationality [non-Qatari Arab] versus [Qatari] } & .169 & .251 & .456 & 1 & .499 & 1.184 & .725 & 1.935 \\
\hline \multicolumn{2}{|c|}{ Nationality [others] versus [Qatari] ${ }^{*}$} & .979 & .310 & 9.977 & 1 & .002 & 2.663 & 1.450 & 4.889 \\
\hline \multicolumn{2}{|l|}{ Constant } & .096 & .249 & 0.150 & 1 & .698 & 1.101 & & \\
\hline
\end{tabular}

${ }^{*}$ It refers to significance at 5 percent level.

TABLE 7: Reported success and logistic model results for the demerit point system strategy.

\begin{tabular}{|c|c|c|c|c|c|c|c|c|c|}
\hline \multirow{2}{*}{ Demerit point system } & \multirow{2}{*}{ Total } & \multicolumn{2}{|c|}{ Gender } & \multicolumn{3}{|c|}{ Age } & \multicolumn{3}{|c|}{ Nationality } \\
\hline & & Male & Female & $18-25$ & $26-50$ & $51+$ & Qatari & Non-Qatari Arab & Others \\
\hline Unsuccessful & 201 & 149 & 52 & 82 & 81 & 38 & 44 & 107 & 50 \\
\hline Successful & 245 & 194 & 51 & 89 & 92 & 64 & 56 & 123 & 66 \\
\hline$\%$ of success & $54.9 \%$ & $56.6 \%$ & $49.5 \%$ & $52.0 \%$ & $53.2 \%$ & $62.7 \%$ & $56.0 \%$ & $53.5 \%$ & $56.9 \%$ \\
\hline \multirow{2}{*}{ Variable } & & \multirow{2}{*}{$B$} & \multirow{2}{*}{ SE } & \multirow{2}{*}{ Wald } & \multirow{2}{*}{$\mathrm{df}$} & \multirow{2}{*}{ Sig. } & Odds ratio & \multicolumn{2}{|c|}{$95 \% \mathrm{CI}$ for $\operatorname{EXP}(B)$} \\
\hline & & & & & & & $\operatorname{Exp}(B)$ & Lower & Upper \\
\hline \multicolumn{2}{|c|}{ Age [26-50] versus [18-25] } & .056 & .220 & .064 & 1 & .800 & 1.057 & .687 & 1.626 \\
\hline \multicolumn{2}{|c|}{ Age [51 or more] versus [18-25] } & .437 & .259 & 2.852 & 1 & .091 & 1.548 & .932 & 2.569 \\
\hline \multicolumn{2}{|c|}{ Gender [female] versus [male] } & -0.282 & .228 & 1.532 & 1 & .216 & 0.754 & 0.482 & 1.179 \\
\hline \multicolumn{2}{|c|}{ Nationality [non-Qatari Arab] versus [Qatari] } & -.059 & .244 & .058 & 1 & .810 & .943 & .584 & 1.522 \\
\hline \multicolumn{2}{|c|}{ Nationality [others] versus [Qatari] } & .029 & .277 & 0.011 & 1 & .918 & 1.029 & .598 & 1.771 \\
\hline \multicolumn{2}{|l|}{ Constant } & .167 & .242 & 0.477 & 1 & .490 & 1.182 & & \\
\hline
\end{tabular}

the violators, which is confirmed in the work of Bates et al. [50].

It is important to achieve this feeling among drivers in order to accomplish a positive behavior change as explained by the speed deterrence theory. According to the theory, drivers tend to change their behavior positively through general and specific speed deterrence. General speed deterrence is a process of influencing potential speed offender, through their fear of detection and the consequences, to avoid speeding. Specific speed deterrence is the process of encouraging frequent offenders, through their actual experience of detection and the consequences, to avoid speeding [51].

However, some participants stated that many people become familiar with the type of vehicle used for mounting mobile speed cameras on the side of the road, and it thus becomes easy to avoid them when one sees the vehicle from a distance. Also, participants pointed out that these types of cameras can cause crashes if a driver is unaware of a speed trap and abruptly slows down upon seeing the portable radar. In addition, participants stated that some people, especially young drivers, share the location of these cameras using social media. Finally, they mentioned that the mobile speed camera enforcement cases are also charged based on the vehicle plate number, so the issues of car owners bearing the consequences of the negligence of drivers and/or dishonest exchanging of black points to innocent drivers will also be encountered. Some participants recommended using this system to give warnings sometimes instead of always giving tickets by combining this strategy with portable speed warning signs.

6.5. Demerit Point System. Only 54.9\% drivers mentioned that the demerit point system (black points) is a successful strategy. This percentage is the lowest among all existing strategies. The results of the binary logistic regression model found no significant relationship between the perceived effectiveness of the demerit points strategy and the gender, age, or nationality of the respondents at the $5 \%$ significance level. Table 7 lists the model estimation and the odds ratio for the independent variables.

The participants stated that the point system is a good preventative tool to enhance safe driving because drivers are worried about their license being suspended or revoked. They also mentioned that the black points are assigned automatically by the traffic department against the driver's license and thus escaping from the penalties is not possible. In addition, participants stated that these points cannot be reversed easily, 
TABLE 8: Reported success and logistic model results for the rewarding safe drivers strategy.

\begin{tabular}{|c|c|c|c|c|c|c|c|c|c|}
\hline \multirow{2}{*}{ Rewarding safe drivers } & \multirow{2}{*}{ Total } & \multicolumn{2}{|c|}{ Gender } & \multicolumn{3}{|c|}{ Age } & \multicolumn{3}{|c|}{ Nationality } \\
\hline & & Male & Female & $18-25$ & $26-50$ & $51+$ & Qatari & Non-Qatari Arab & Others \\
\hline Unsuccessful & 101 & 95 & 6 & 38 & 40 & 23 & 22 & 58 & 21 \\
\hline Successful & 345 & 248 & 97 & 133 & 133 & 79 & 78 & 172 & 95 \\
\hline$\%$ of success & $77.4 \%$ & $72.3 \%$ & $94.2 \%$ & $77.8 \%$ & $76.9 \%$ & $77.5 \%$ & $78.0 \%$ & $74.8 \%$ & $81.9 \%$ \\
\hline \multirow{2}{*}{ Variable } & & \multirow{2}{*}{$B$} & \multirow{2}{*}{ SE } & \multirow{2}{*}{ Wald } & \multirow{2}{*}{ df } & \multirow{2}{*}{ Sig. } & Odds ratio & \multicolumn{2}{|c|}{$95 \% \mathrm{CI}$ for $\operatorname{EXP}(B)$} \\
\hline & & & & & & & $\operatorname{Exp}(B)$ & Lower & Upper \\
\hline \multicolumn{2}{|c|}{ Age [26-50] versus [18-25] } & -.230 & .269 & .731 & 1 & .393 & 0.795 & .470 & 1.345 \\
\hline \multicolumn{2}{|c|}{ Age [51 or more] versus [18-25] } & -.132 & .311 & .180 & 1 & .672 & .877 & .477 & 1.612 \\
\hline \multicolumn{2}{|c|}{ Gender [female] versus [male] ${ }^{*}$} & 1.885 & .440 & 18.306 & 1 & .000 & 6.583 & 2.777 & 15.609 \\
\hline \multicolumn{2}{|c|}{ Nationality [non-Qatari Arab] versus [Qatari] } & -.332 & .294 & 1.278 & 1 & .258 & .717 & .403 & 1.276 \\
\hline \multicolumn{2}{|c|}{ Nationality [others] versus [Qatari] } & .194 & .349 & 0.310 & 1 & .578 & 1.214 & 613 & 2.404 \\
\hline \multicolumn{2}{|l|}{ Constant } & 1.200 & .294 & 16.703 & 1 & .000 & 3.321 & & \\
\hline
\end{tabular}

${ }^{*}$ It refers to significance at 5 percent level.

whereas fines can be paid and waived off immediately. They also stated that there are many traffic offenses for which a driver's license can accumulate black points.

The disadvantages reported by participants include that once the violation is recorded, if the car owner fails to provide clear evidence that the vehicle was not in his custody at the time of the violation and if the vehicle was in the custody of another person, the car owner will have to bear the consequences. They also mentioned that the black points are charged based on the video captured during the violation. Therefore, some drivers may fraudulently place the blame on their chauffeurs or friends and get black points against the guiltless driver's license. Some respondents also felt that black points are assigned unfairly for certain violations, such as illegal parking.

\section{Assessment of Proposed Strategies}

7.1. Rewarding Safe Drivers. The strategy of rewarding safe drivers emerged as the most successful strategy, with a $77.4 \%$ of participants perceiving it as effective. A high success rate for this strategy was projected by all demographics, even high-income Qataris. The analysis found a significant relationship between the perceived effectiveness of this strategy and gender at the $5 \%$ significance level.

Table 8 lists the model estimation and the odds ratio for the independent variables. The model showed that female drivers are 6.5 times more likely than male drivers to perceive the reward strategy as effective.

Respondents felt that this strategy will better reduce crashes than focusing on punishing drivers and collecting fees from them because rewarding drivers will motivate them to improve their driving skills, abide by the traffic rules, and be more relaxed while driving. Some participants stated that clean records should be rewarded with lower car insurance rates and better car financing rates. The respondents also mentioned that this strategy would encourage some drivers to set and achieve personal driving goals. In addition, the participants argued that a driver who gets rewards will motivate others to become better drivers. The respondents felt that if the rewards are recorded on the driver's license, this can create a good impression when one is stopped by a police officer for a traffic violation or when one is buying car insurance.

On the other hand, respondents were worried that this strategy would not be successful with the high number of visitors that visit Qatar every year because drivers visiting the country with an international license will not able to benefit from this strategy. Some drivers argued that safe driving is everyone's responsibility and that there should not be incentives for following rules, only strict penalties for violating them.

7.2. Additional Automated Enforcement Methods. The strategy of additional automated enforcement methods emerged as the second most successful strategy, with $72 \%$ of participants perceiving it as successful. The results revealed no significant relationship between this strategy and gender or age at the $5 \%$ significance level. Based on the effect model, the binary logistic regression model identified significant factors directly associated with the proposed strategies being successful.

Table 9 lists the model estimation and the odds ratio for the independent variables. The model showed that the odds of non-Qatari Arabs accepting this strategy were 48\% less than the odds of Qataris accepting it. Similarly, the odds of other nationalities accepting this strategy are $30 \%$ less than the odds of Qataris accepting it.

The respondents indicated that additional automated enforcement methods will be successful in reducing crashes. The respondents felt that these types of solutions are the future and will be implemented in different countries and that Qatar should keep up with these countries. They also stated that these devices are fair and argument-proof; they can show drivers exactly how they committed the violations.

However, some participants were concerned that as people become familiar with the setup of the new proposed methods, drivers will find ways to avoid them. Others were concerned that the proposed methods might cause crashes when drivers abruptly react upon seeing the enforcement equipment, without warning to surrounding vehicles. 
TABLE 9: Reported success and logistic model results for additional automated enforcement methods strategy.

\begin{tabular}{|c|c|c|c|c|c|c|c|c|c|}
\hline \multirow{2}{*}{$\begin{array}{l}\text { Additional automated } \\
\text { enforcement methods }\end{array}$} & \multirow{2}{*}{ Total } & \multicolumn{2}{|c|}{ Gender } & \multicolumn{3}{|c|}{ Age } & \multicolumn{3}{|c|}{ Nationality } \\
\hline & & Male & Female & $18-25$ & $26-50$ & $51+$ & Qatari & Non-Qatari Arab & Others \\
\hline Unsuccessful & 125 & 98 & 27 & 44 & 48 & 33 & 16 & 64 & 45 \\
\hline Successful & 321 & 245 & 76 & 127 & 125 & 69 & 84 & 166 & 71 \\
\hline$\%$ of success & $72.0 \%$ & $71.4 \%$ & $73.8 \%$ & $74.3 \%$ & $72.3 \%$ & $67.6 \%$ & $84.0 \%$ & $72.2 \%$ & $61.2 \%$ \\
\hline \multirow{2}{*}{\multicolumn{2}{|c|}{ Variable }} & \multirow{2}{*}{$B$} & \multirow{2}{*}{ SE } & \multirow{2}{*}{ Wald } & \multirow{2}{*}{$\mathrm{df}$} & \multirow{2}{*}{ Sig. } & Odds ratio & \multicolumn{2}{|c|}{ 95\% CI for $\operatorname{EXP}(B)$} \\
\hline & & & & & & & $\operatorname{Exp}(B)$ & Lower & Upper \\
\hline \multicolumn{2}{|c|}{ Age [26-50] versus [18-25] } & -.094 & .251 & .141 & 1 & .707 & 0.910 & .556 & 1.488 \\
\hline \multicolumn{2}{|c|}{ Age [51 or more] versus [18-25] } & -.283 & .282 & 1.008 & 1 & .315 & .754 & .434 & 1.309 \\
\hline \multicolumn{2}{|c|}{ Gender [female] versus [male] } & 0.169 & .259 & 0.425 & 1 & .514 & 1.184 & 0.712 & 1.969 \\
\hline \multicolumn{2}{|c|}{ Nationality [non-Qatari Arab] versus [Qatari] } & -.738 & .312 & 5.576 & 1 & .018 & .478 & .259 & 0.882 \\
\hline \multicolumn{2}{|c|}{ Nationality [others] versus [Qatari] ${ }^{*}$} & -1.198 & .334 & 12.880 & 1 & .000 & .302 & .157 & 0.581 \\
\hline \multicolumn{2}{|c|}{ Constant } & 1.740 & .315 & 30.559 & 1 & .000 & 5.695 & & \\
\hline
\end{tabular}

${ }^{*}$ It refers to significance at 5 percent level.

TABLE 10: Reported success and logistic model results for the community service for traffic tickets strategy.

\begin{tabular}{|c|c|c|c|c|c|c|c|c|c|}
\hline \multirow{2}{*}{ Community service for traffic tickets } & \multirow{2}{*}{ Total } & \multicolumn{2}{|c|}{ Gender } & \multicolumn{3}{|c|}{ Age } & \multicolumn{3}{|c|}{ Nationality } \\
\hline & & Male & Female & $18-25$ & $26-50$ & $51+$ & Qatari & Non-Qatari Arab & Others \\
\hline Unsuccessful & 155 & 114 & 41 & 67 & 62 & 26 & 41 & 95 & 19 \\
\hline Successful & 291 & 129 & 62 & 104 & 111 & 76 & 59 & 135 & 97 \\
\hline$\%$ of success & $65.2 \%$ & $37.6 \%$ & $60.2 \%$ & $60.8 \%$ & $64.2 \%$ & $74.5 \%$ & $59.0 \%$ & $58.7 \%$ & $83.6 \%$ \\
\hline \multirow{2}{*}{\multicolumn{2}{|c|}{ Variable }} & \multirow{2}{*}{$B$} & \multirow{2}{*}{ SE } & \multirow{2}{*}{ Wald } & \multirow{2}{*}{ df } & \multirow{2}{*}{ Sig. } & Odds ratio & \multicolumn{2}{|c|}{$95 \%$ CI for $\operatorname{EXP}(B)$} \\
\hline & & & & & & & $\operatorname{Exp}(B)$ & Lower & Upper \\
\hline \multicolumn{2}{|l|}{ Age [26-50] versus [18-25] } & .054 & .232 & .054 & 1 & .817 & 1.055 & .669 & 1.664 \\
\hline \multicolumn{2}{|l|}{ Age [51 or more] versus [18-25] } & .527 & .284 & 3.427 & 1 & .064 & 1.693 & .970 & 2.957 \\
\hline \multicolumn{2}{|c|}{ Gender [female] versus [male] } & -0.297 & .242 & 1.509 & 1 & .219 & 0.743 & 0.463 & 1.193 \\
\hline \multicolumn{2}{|c|}{ Nationality [non-Qatari Arab] versus [Qatari] } & .036 & .248 & .021 & 1 & .885 & 1.036 & .638 & 1.684 \\
\hline \multicolumn{2}{|c|}{ Nationality [others] versus [Qatari] ${ }^{*}$} & 1.270 & .325 & 15.245 & 1 & .000 & 3.560 & 1.882 & 6.734 \\
\hline \multicolumn{2}{|l|}{ Constant } & .275 & .248 & 1.231 & 1 & .267 & 1.317 & & \\
\hline
\end{tabular}

* It refers to significance at 5 percent level.

7.3. Community Service for Traffic Tickets. The strategy of additional automated enforcement methods emerged as the third most highly perceived successful strategy, with $65.2 \%$ participants perceiving it as successful. The results of the analysis found no significant relationship between this strategy and the gender or age of participants at the $5 \%$ significance level. Table 10 lists the binary logistic regression model estimation and the odds ratio for the independent variables. The model showed that drivers from other nationalities are 3.6 times more likely to accept community service for traffic tickets than Qatari drivers.

Regarding advantages, the respondents mentioned that, in Qatar, one of the richest countries, paying fines for traffic tickets may not work because many drivers can easily afford to pay the fines. However, the fear of doing the mandatory community service, which introduces a prestige issue, will encourage the avoidance of traffic violations. Some of the participants also felt that community service for traffic tickets might benefit society and many nonprofit organizations that need volunteers. It was also mentioned that this strategy would allow people experience the other aspects of life, which they may not have seen otherwise in this rich country.

On the other hand, some concerns were raised by the participants regarding cultural issues. Custom prohibits women from performing most community services, which will cause some cultural problems. In addition, the participants mentioned that the drivers might find reasons to escape the penalty, for example, by pretending to be sick. Finally, there were concerns that the types of community service may be limited in Qatar, which would limit the effectiveness of this strategy.

7.4. Defensive Driving School. Defensive driving school was revealed to be the least successful strategy among the four proposed strategies, with $53.6 \%$ of participants perceiving it as successful rate. There is a strong relationship between perception of this strategy's efficacy and the nationality of the respondents. The Qatari respondents found this strategy 
TABLE 11: Reported success and logistic model results for the defensive driving school strategy.

\begin{tabular}{|c|c|c|c|c|c|c|c|c|c|}
\hline \multirow{2}{*}{ Defensive driving school } & \multirow{2}{*}{ Total } & \multicolumn{2}{|c|}{ Gender } & \multicolumn{3}{|c|}{ Age } & \multicolumn{3}{|c|}{ Nationality } \\
\hline & & Male & Female & $18-25$ & $26-50$ & $51+$ & Qatari & Non-Qatari Arab & Others \\
\hline Unsuccessful & 207 & 154 & 53 & 76 & 78 & 53 & 35 & 106 & 66 \\
\hline Successful & 239 & 129 & 50 & 95 & 95 & 49 & 65 & 124 & 50 \\
\hline$\%$ of success & $53.6 \%$ & $37.6 \%$ & $48.5 \%$ & $55.6 \%$ & $54.9 \%$ & $48.0 \%$ & $65.0 \%$ & $53.9 \%$ & $43.1 \%$ \\
\hline \multirow{2}{*}{ Variable } & & \multirow{2}{*}{$B$} & \multirow{2}{*}{ S.E. } & \multirow{2}{*}{ Wald } & \multirow{2}{*}{ df } & \multirow{2}{*}{ Sig. } & Odds ratio & \multicolumn{2}{|c|}{$95 \%$ CI for $\operatorname{EXP}(B)$} \\
\hline & & & & & & & $\operatorname{Exp}(B)$ & Lower & Upper \\
\hline \multicolumn{2}{|l|}{ Age [26-50] versus [18-25] } & .018 & .223 & .007 & 1 & .936 & 1.018 & .658 & 1.576 \\
\hline \multicolumn{2}{|c|}{ Age [51 or more] versus [18-25] } & -.254 & .256 & .984 & 1 & .321 & .775 & .469 & 1.282 \\
\hline \multicolumn{2}{|c|}{ Gender [female] versus [male] } & -0.243 & .229 & 1.125 & 1 & .289 & 0.784 & 0.500 & 1.229 \\
\hline \multicolumn{2}{|c|}{ Nationality [non-Qatari Arab] versus [Qatari] } & -.449 & .251 & 3.205 & 1 & .073 & .638 & .391 & 1.043 \\
\hline \multicolumn{2}{|c|}{ Nationality [others] versus [Qatari] ${ }^{*}$} & -.875 & .282 & 9.599 & 1 & .002 & .417 & .240 & 0.725 \\
\hline \multicolumn{2}{|l|}{ Constant } & .714 & .251 & 8.097 & 1 & .004 & 2.043 & & \\
\hline
\end{tabular}

${ }^{*}$ It refers to significance at 5 percent level.

more successful than other nationalities. Table 11 lists the model estimation and the odds ratio for the independent variables. The results found no significant relationship between this strategy and gender or age at the 5\% significance level. The model shows that other nationalities are $42 \%$ more likely to accept the defensive driving school strategy than Qatari nationals.

The participants stated that enrolling in driving school again might be a good strategy. They also mentioned that the traffic school instructors would help to explain any new changes in the traffic laws and remind the drivers about the original rules. Respondents also pointed out that because Qatar does not require a knowledge test for drivers to renew their licenses, some drivers may not update their knowledge regularly. Moreover, without regular refresher tests, the knowledge acquired when taking the driver license test may deteriorate over time. They also stated that the time associated with the defensive school would be a motivation for the drivers to avoid committing these types of traffic violations. Some participants recommended that drivers take another theoretical test at the time of license renewal to ensure that they are aware of the latest traffic rules. However, participants also mentioned that drivers who have already attended driving school and are aware of all the traffic rules would not benefit much from classes. Some participants also mentioned that drivers are already aware of the proper driving rules, but they have behavioral issues.

\section{Conclusions and Recommendations}

The purpose of this study was to ascertain drivers' perceptions of five existing and four proposed police enforcement strategies and associated penalties and rewards in Qatar. The five existing traffic strategies are RLCs, fixed-speed enforcement cameras, police enforcement, mobile speed cameras, and a demerit point system. The results show that RLCs were mentioned as the most successful existing strategy. The high violation fine and the automation of the system were mentioned as the main reasons that this strategy is the most successful. These results agree with the studies showing that the public will cooperate and comply with the law if the public agencies use procedural justice to deal with the public $[52,53]$. According to the responses of the participants, increasing the number of RLCs to cover more signalized intersections and emphasizing their location, in addition to fixing the cameras as soon as they are damaged or hit by a vehicle, will make this strategy more successful.

Three of the strategies, fixed-speed enforcement cameras, police enforcement, and mobile speed cameras, were conferred almost the same rate of perceived success. Some recommendations to improve the police enforcement strategy included adding more officers on the road, motivating police officers to work efficiently, training police officers in new and better technologies, and training police officers to improve their interpersonal skills. There were some concerns about the fairness of the police, which needs to be addressed. The public trust is important for the people to accept the police enforcement and feel obligated to obey the rules when they believe the institution acts according to a shared moral purpose with the citizens $[54,55]$.

In terms of the fixed-speed cameras, the respondents recommended adding more cameras on existing and new roads, repairing existing cameras as soon as they are damaged, and ensuring good visibility for the existing and new cameras. For the mobile cameras, additional cameras are also needed, in addition to changing the types of vehicles used to mount the mobile speed cameras. The demerit point system was perceived as the least successful strategy. The main concern of the participants was the punishment avoidance, that is, the possibility of tricking the system, since the points were placed on the vehicle license and not the driver. Previous research suggests that experiences of punishment avoidance may have a stronger influence upon risky driving behavior than experiences of punishment [49]. Therefore, this issue should be further investigated by the Traffic Department at the MOI or in future research to enhance this strategy.

Regarding the proposed strategies, rewarding safe drivers was selected by the participants as the most successful proposed strategy, and it should be considered for implementation. The results agree with a previous study that indicates 
that rewards have a strong positive effect on safe driving behavior [56]. A key element in the success of this strategy is not to delay rewarding the safe drivers. Otherwise, it is not likely to produce useful results [35]. The results show that this strategy is also accepted by Qatari nationals, despite their high-income.

The respondents would also like to see additional automated enforcement methods installed on the roads of Qatar; this strategy was the second most successful proposed strategy. Regarding community service for traffic tickets, this strategy may face strong rejection among a high percentage of the population, especially among Qatari nationals, for cultural and social reasons. Finally, the least successful proposed strategy according to the participants was defensive driving school.

The results of this study can be used to guide the development and enhancement of the existing strategies and the implementation of future strategies being introduced in the traffic system. Moreover, this study is the first of its kind in Qatar, and it thus reflects special social and cultural characteristics, which also makes the outcomes of this study applicable to other countries in this area.

The main limitation of this study is one that most questionnaire-based analyses suffer from. Some respondents might be reluctant to provide truthful answers due to the pressure to provide more socially acceptable answers. Fortunately, this does not seem to be a major issue in this study; the descriptive statistics show that a high percentage of the participants (close to $50 \%$ in some cases) found several strategies unsuccessful. Future research should consider the evaluations of any of the proposed countermeasures as they are introduced.

\section{Competing Interests}

The author declares that there is no conflict of interests regarding the publication of this paper.

\section{References}

[1] C. J. Murray and A. D. Lopez, The Global Burden of Disease, Harvard School of Public Health for the World Health Organization and the World Bank, Cambridge, Mass, USA, 1996.

[2] K. Shaaban and H. M. Hassan, "Modeling significant factors affecting Commuters' perspectives and propensity to use the new proposed metro service in Doha," Canadian Journal of Civil Engineering, vol. 41, no. 12, pp. 1054-1064, 2014.

[3] K. Shaaban and E. Radwan, "Rebuilding the transportation system in the city of Doha," Journal of Traffic and Logistics Engineering, vol. 2, no. 3, pp. 241-247, 2014.

[4] "Driver's attitude towards new traffic law in the state of qatar," in Proceedings of the WAPOR 65th Annual Conference, E. Elawad, A. Dop, L. Kien, and K. Shaaban, Eds., Hong Kong, June 2012.

[5] B. Tasch, "The 25 richest countries," ranked, 2016.

[6] WorldsAtlas, The Richest Countries in the World 2016, http://www.worldatlas.com/articles/100008-the-richest-nationsin-the-world-the-ten-richest-countries-on-the-planet.

[7] BQ Magazine, "Population of Qatar by nationality," 2013, http:// www.bq-magazine.com/economy/2013/12/population-qatar.
[8] F. De Bel-Air, "Demography, migration, and labour market in Qatar," Gulf Research Center, Contract No.: GLMM-ENNo.8/2014, 2014.

[9] Statistics QMoDPa, Final Results of Household Expenditure and Income Survey (2012-2013), 2014.

[10] MDPS, Qatar Population and Social Statistics, Qatar's Ministry of Development, Planning and Statistics, 2015.

[11] L. F. P. de Figueiredo, S. Rasslan, V. Bruscagin, R. Cruz Jr., and M. R. e Silva, "Increases in fines and driver licence withdrawal have effectively reduced immediate deaths from trauma on Brazilian roads: first-year report on the new traffic code," Injury, vol. 32, no. 2, pp. 91-94, 2001.

[12] O. T. Hussain, M. S. Nayyar, F. A. Brady, J. C. Beirne, and L. F. A. Stassen, "Speeding and maxillofacial injuries: impact of the introduction of penalty points for speeding offences," British Journal of Oral and Maxillofacial Surgery, vol. 44, no. 1, pp. 1519, 2006.

[13] J. Pulido, P. Lardelli, L. De La Fuente, V. M. Flores, F. Vallejo, and E. Regidor, "Impact of the demerit point system on road traffic accident mortality in Spain," Journal of Epidemiology and Community Health, vol. 64, no. 3, pp. 274-276, 2010.

[14] S. Farchi, F. Chini, P. G. Rossi, L. Camilloni, P. Borgia, and G. Guasticchi, "Evaluation of the health effects of the new driving penalty point system in the Lazio Region, Italy, 2001-4," Injury Prevention, vol. 13, no. 1, pp. 60-64, 2007.

[15] K. Shaaban, "Comparative study of road traffic rules in Qatar compared to Western Countries," in Proceedings of the Transport Research Arena 2012, vol. 48, pp. 992-999, Athens, Greece, 2012.

[16] S. D. Lawson, Red-light running: accidents and surveillance cameras, 1991.

[17] H. W. McGee and K. A. Eccles, Impact of Red Light Camera Enforcement on Crash Experience, Transportation Research Board, 2003.

[18] F. M. Council, B. N. Persaud, K. A. Eccles, C. Lyon, and M. S. Griffith, "Safety evaluation of red-light cameras," Tech. Rep., 2005.

[19] B. Persaud, F. M. Council, C. Lyon, K. Eccles, and M. Griffith, "Multijurisdictional safety evaluation of red light cameras," Transportation Research Record, no. 1922, pp. 29-37, 2005.

[20] R. A. Retting, A. F. Williams, C. M. Farmer, and A. F. Feldman, "Evaluation of red light camera enforcement in Oxnard, California," Accident Analysis \& Prevention, vol. 31, no. 3, pp. 169-174, 1999.

[21] R. A. Retting, A. F. Williams, C. M. Farmer, and A. F. Feldman, "Evaluation of red light camera enforcement in Fairfax, Va., USA," ITE Journal (Institute of Transportation Engineers), vol. 69, no. 8, 1999.

[22] A. Hooke, J. Knox, and D. Portas, Cost Benefit Analysis of Traffic Light \& Speed Cameras, Home Office, Police Research Group, London, UK, 1996.

[23] MOI. Qatar Traffic Law as Promulgated by Decree-Law No. 19 of 2007: Ministry of Interior, 2007, http://www.almeezan.qa/ LawView.aspx? opt\&LawID=3993\&language=en.

[24] G. Chen, W. Meckle, and J. Wilson, "Speed and safety effect of photo radar enforcement on a highway corridor in British Columbia," Accident Analysis \& Prevention, vol. 34, no. 2, pp. 129-138, 2002.

[25] R. Elvik, "The importance of confounding in observational before-and-after studies of road safety measures," Accident Analysis \& Prevention, vol. 34, no. 5, pp. 631-635, 2002. 
[26] P. G. Champness, M. C. Sheehan, and L.-M. Folkman, “Time and distance halo effects of an overtly deployed mobile speed camera," in Proceedings of the Road Safety Research, Policing and Education Conference, Wellington, New Zealand, November 2005.

[27] S. Y. Ali, O. Al-Saleh, and P. A. Koushki, "Effectiveness of automated speed-monitoring cameras in Kuwait," Transportation Research Record, no. 1595, pp. 20-26, 1997.

[28] P. Liu, X. Zhang, W. Wang, and C. Xu, "Driver response to automated speed enforcement on rural highways in China," Transportation Research Record, no. 2265, pp. 109-117, 2011.

[29] S. M. Christie, R. A. Lyons, F. D. Dunstan, and S. J. Jones, "Are mobile speed cameras effective? A controlled before and after study," Injury Prevention, vol. 9, no. 4, pp. 302-306, 2003.

[30] M. D. Keall, L. J. Povey, and W. J. Frith, "The relative effectiveness of a hidden versus a visible speed camera programme," Accident Analysis \& Prevention, vol. 33, no. 2, pp. 277-284, 2001.

[31] A. P. Jones, V. Sauerzapf, and R. Haynes, "The effects of mobile speed camera introduction on road traffic crashes and casualties in a rural county of England," Journal of Safety Research, vol. 39, no. 1, pp. 101-110, 2008.

[32] R. Tay, "General and specific deterrent effects of traffic enforcement: do we have to catch offenders to reduce crashes?" Journal of Transport Economics and Policy, vol. 39, no. 2, pp. 209-223, 2005.

[33] E. Chen and A. Tarko, "Analysis of crash frequency in work zones with focus on police enforcement," Transportation Research Record, no. 2280, pp. 127-134, 2012.

[34] D. R. Axup, "Enforcement-a review of Australian techniques," in Proceedings of the 15th Australian Road Research Board (ARRB) Conference, vol. 15, no. 7 of Australian Road Research Board, pp. 26-31, Darwin, Australia, August 1990.

[35] P. M. Hurst, "Can anyone reward safe driving?" Accident Analysis \& Prevention, vol. 12, no. 3, pp. 217-220, 1980.

[36] EmiratesNews, "1,000 Drivers win prizes in Dubai Traffic Police's 'white points' contest for 2013," 2014, http://www .emirates247.com/news/emirates/1-000-drivers-win-prizes-indubai-traffic-police-s-white-points-contest-for-2013-2014-03-201.542389 .

[37] "Traffic policing and road safety for individuals and for populations," in Proceedings of the Australasian College of Road Safety Conference, A Safe System: Expanding the Reach: Australasian College of Road Safety National Conference (ACRS '12), I. J. Faulks, M. Lane, and J. D. Irwin, Eds., Sydney, Australia, 2012.

[38] "Addressing issues of driver distraction in traffic offender management," in Proceedings of the Australasian College of Road Safety Conference 2012, I. Faulks, Ed., Sydney, Australia, 2012.

[39] DMV.ORG, Defensive Driving in North Dakota, http://www .dmv.org/defensive-driving/faq.php.

[40] Arizona_Traffic_School, Traffic Survival School, https://www .aztrafficschools.com/classes/survival/.

[41] A. K. Lund and A. F. Williams, "A review of the literature evaluating the defensive driving course," Accident Analysis and Prevention, vol. 17, no. 6, pp. 449-460, 1985.

[42] S. Payne, A. Brownlea, and A. Hall, Evaluation of Queensland Defensive Driving Course, Department of Transport, Office of Road Safety, 1984.

[43] U.S. Department of Transportation National Highway Traffic Safety Administration and America USo, Community Service Restitution Programs for Alcohol Related Traffic OffendersVolume II: Case Studies and Resource Materials, 1985.
[44] FoxBusiness. Pay your speeding ticket by picking up litter, 2011, http://www.foxbusiness.com/features/2011/06/24/pay-your-speeding-ticket-by-picking-up-litter.html.

[45] HeraldSun. Victoria Police gets new traffic cameras to nab motorists using mobile phones or not wearing seat belts from 700m away, 2014, http://www.heraldsun.com.au/news/laworder/victoria-police-gets-new-traffic-cameras-to-nab-motorists-using-mobile-phones-or-not-wearing-seat-belts-from-700maway/story-fni0fee2-1226884287563.

[46] RoadTrafficTechnology.com, Dubai Traffic Police: 'Vitronic Speed Camera Six Times More Efficient Than Radar', 2014, http://www.roadtraffic-technology.com/contractors/photo_enforcement/vitronic-photo-enforcement/pressdubai-traffic-policevitronic-speed-camera.html.

[47] G. D. Israel, Determining Sample Size, University of Florida Cooperative Extension Service, Institute of Food and Agriculture Sciences, EDIS, 1992.

[48] P. McCullagh and J. A. Nelder, Generalized Linear Models, CRC Press, 1989.

[49] B. Scott-Parker, B. Watson, M. J. King, and M. K. Hyde, "Punishment avoidance and intentional risky driving behaviour: what are the implications for 'getting away with it'?" in Psychology of Punishment: New Research, N. Castro, Ed., pp. 55-78, Nova Science Publishers, New York, NY, USA, 2013.

[50] L. Bates, S. Allen, and B. Watson, "The influence of the elements of procedural justice and speed camera enforcement on young novice driver self-reported speeding," Accident Analysis \& Prevention, vol. 92, pp. 34-42, 2016.

[51] M. H. Cameron and J. T. Sanderson, "Review of police operations for traffic law enforcement," Tech. Rep. TS 82/5, Royal Automobile Club of Victoria, Melbourne, Australia, 1982.

[52] J. M. Barkworth and K. Murphy, "Procedural justice policing and citizen compliance behaviour: the importance of emotion," Psychology, Crime \& Law, vol. 21, no. 3, pp. 254-273, 2014.

[53] B. Bradford, "Policing and social identity: procedural justice, inclusion and cooperation between police and public," Policing and Society, vol. 24, no. 1, pp. 22-43, 2014.

[54] M. Hough, J. Jackson, B. Bradford, A. Myhill, and P. Quinton, "Procedural justice, trust, and institutional legitimacy," Policing, vol. 4, no. 3, pp. 203-210, 2010.

[55] J. Jackson, B. Bradford, M. Hough, A. Myhill, P. Quinton, and T. R. Tyler, "Why do people comply with the law?" British Journal of Criminology, vol. 52, no. 6, pp. 1051-1071, 2012.

[56] U. Mazureck and J. Hattem, "Rewards for safe driving behavior: influence on following distance and speed," Transportation Research Record, vol. 1980, pp. 31-38, 2006. 


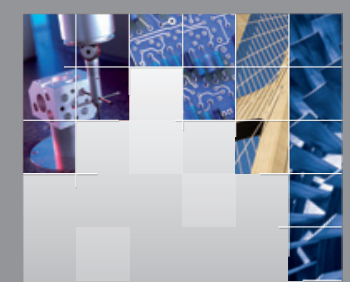

\section{Enfincering}
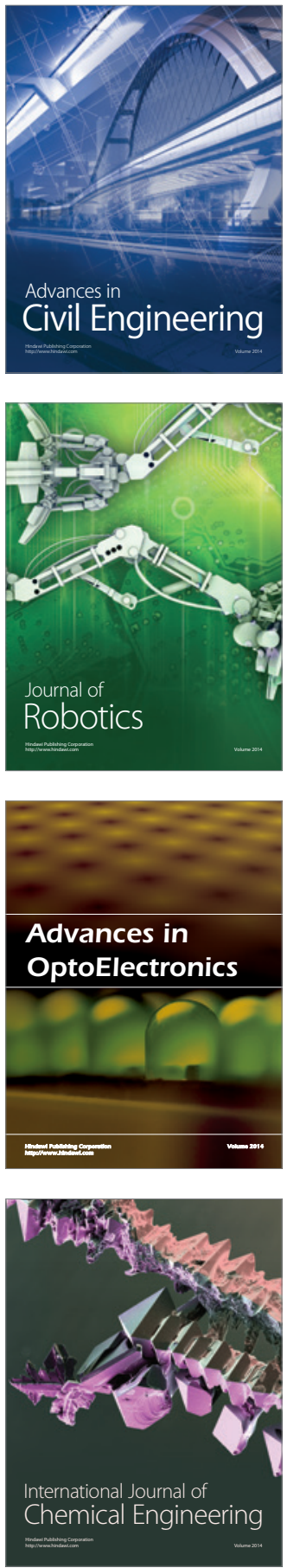

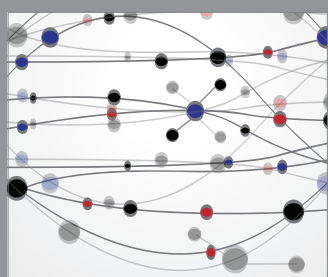

The Scientific World Journal

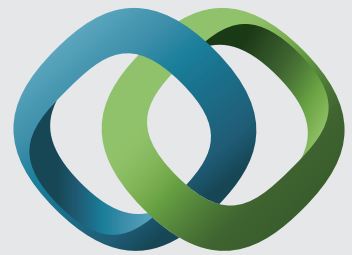

\section{Hindawi}

Submit your manuscripts at

https://www.hindawi.com
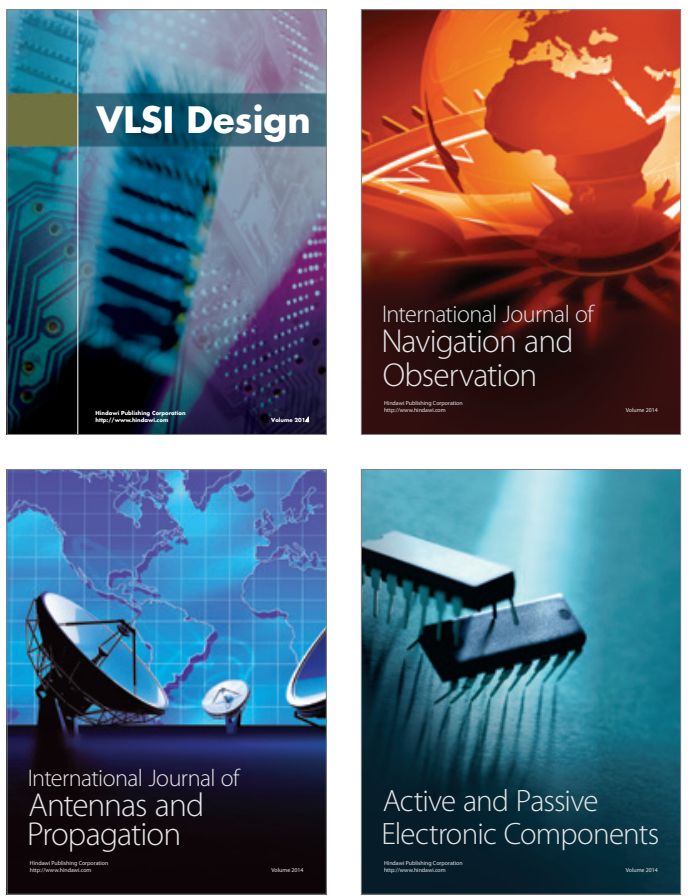
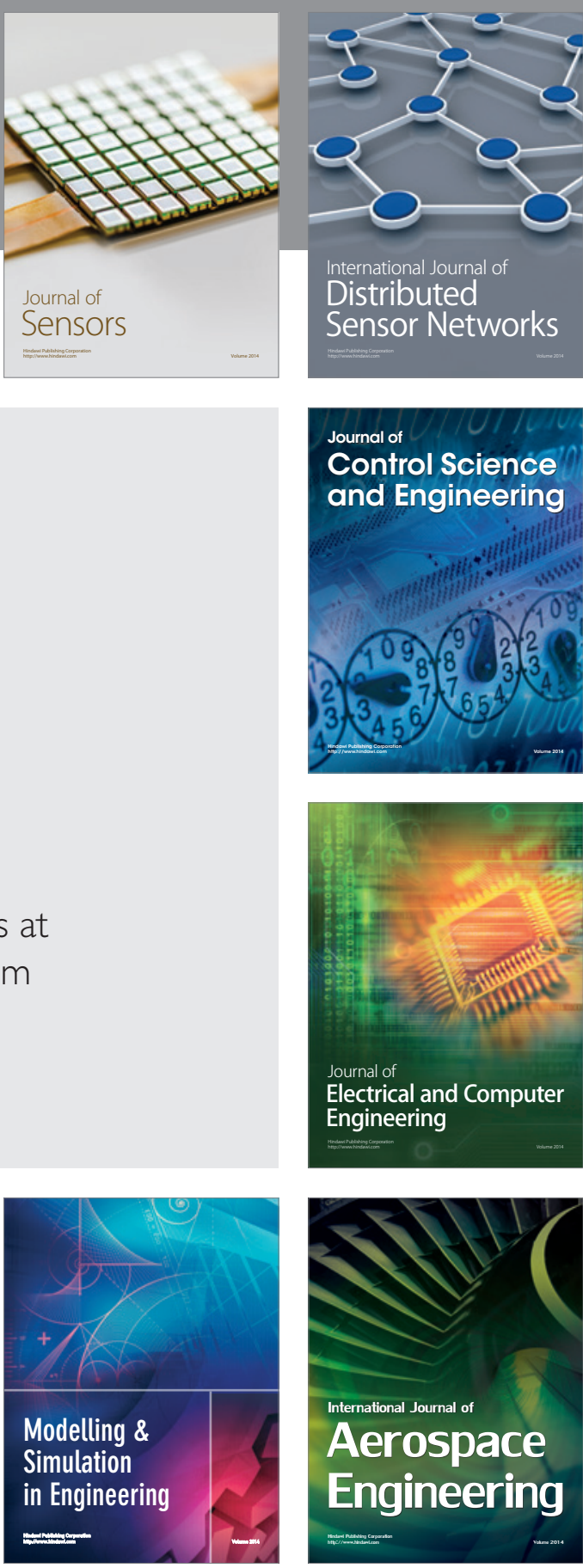

International Journal of

Distributed

Sensor Networks

$-$

Joumal of

Control Science

and Engineering
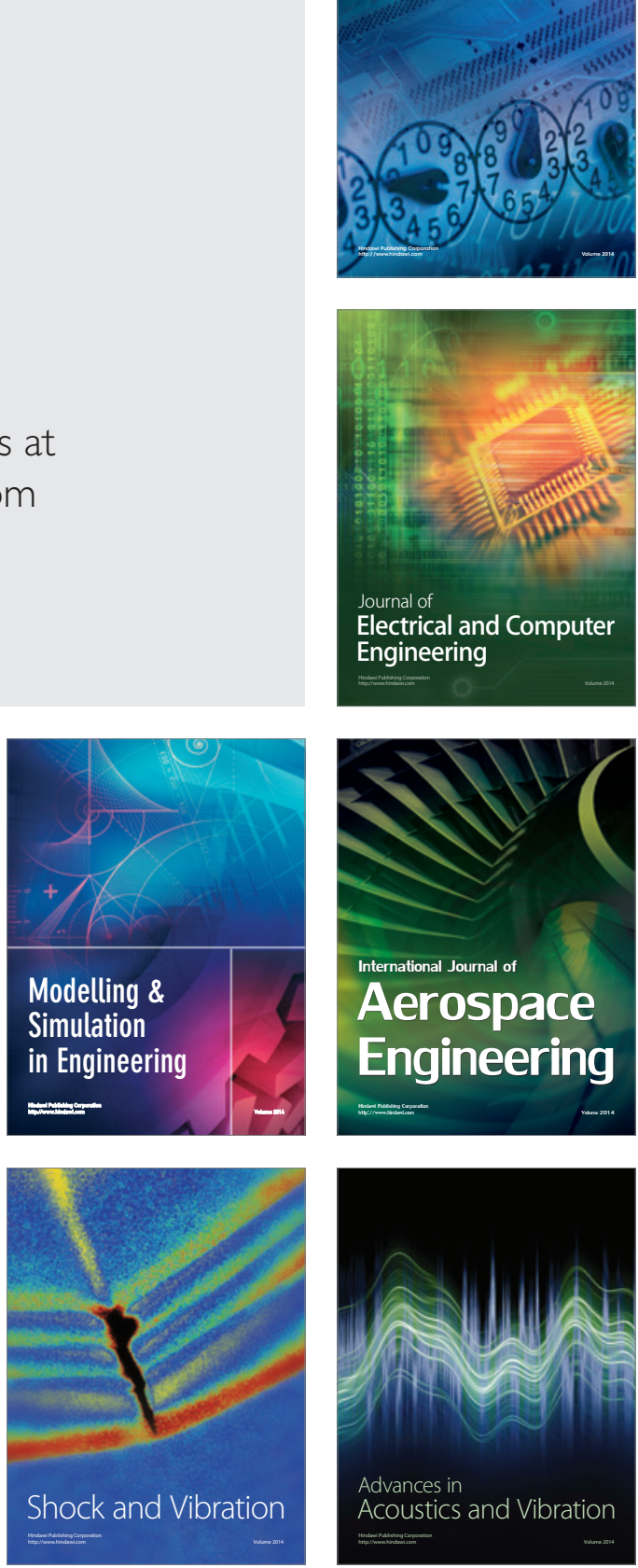